\title{
EVALUASI KONDISI PERKERASAN JALAN NASIONAL SERTA ALTERNATIF PENANGANANNYA (STUDI KASUS : JALAN DAAN MOGOT)
}

\author{
Alpin Chayan Soeseno ${ }^{1}$ dan Anissa Noor Tajudin ${ }^{2}$ \\ ${ }^{1}$ Program Studi Sarjana Teknik Sipil, Universitas Tarumanagara, Jl. Letjen S. Parman No.1 Jakarta \\ alpin.325150082@stu.untar.ac.id \\ ${ }^{2}$ Program Studi Sarjana Teknik Sipil, Universitas Tarumanagara, Jl. Letjen S. Parman No.1 Jakarta \\ anissat@ft.untar.ac.id
}

Masuk: 30-06-2021, revisi: 12-07-2021, diterima untuk diterbitkan: 30-08-2021

\begin{abstract}
Daan Mogot street is part of the National Road Route One (1). Daan Mogot street (Section Number: 2000111) under study is a $2.5 \mathrm{KM}$ two-way four-lane flexible pavement road, with a lane width of $3.5 \mathrm{~m}$. The location chosen is the point of the worst congestion on Daan Mogot street, with the most road damage conditions. The purpose of this study is to analyze the condition of the road pavement and what treatment should we do for the damage on Daan Mogot street. The stages in this road pavement research are divided into 2 stages, firstly calculating the damage on the road, and choose alternative treatment using existing methods. The method used is the Pavement Condition Index (IKP) method and evaluates the handling of damage in the last 3 years. The result of the research is that the most damage is patch and hole damage, and the IKP value for each research unit can be seen that the pavement quality varies, from the level of Very Poor, Poor, Fair, Satisfactory, to Good. The average IKP value on Daan Mogot street in the direction of Tangerang from KM+14,000 to KM+16,500 is 87.09 with a Good condition class.
\end{abstract}

Keywords: Daan Mogot Street; road damage and IKP

\begin{abstract}
ABSTRAK
Jalan Daan Mogot merupakan bagian dari Jalan Nasional Rute Satu (1). Jalan Daan Mogot (Nomor Ruas : 2000111) yang diteliti merupakan jalan dengan perkerasan lentur sepanjang 2,5 KM dua arah empat lajur, dengan lebar perlajur 3,5 m. Lokasi yang dipilih merupakan titik kemacetan terparah di Jalan Daan Mogot, dengan kondisi kerusakan jalan terbanyak. Tujuan penelitian ini untuk menganalisis kondisi perkerasan jalan dan penanganan apa yang harus kita lakukan terhadap kerusakan yang terjadi di Jalan Daan Mogot. Tahapan dalam penelitian perkerasan jalan ini dibagi menjadi 2 tahapan yaitu, pertama menghitung kerusakan yang ada di jalan tersebut, dan menentukan alternatif penanganan yang tepat dengan menggunakan metode-metode yang ada. Metode yang dipakai adalah metode Indeks Kondisi Perkerasan (IKP) dan melakukan evaluasi penanganan kerusakan dalam 3 tahun terakhir. Hasil penelitian yang diperoleh adalah kerusakan terbanyak ada pada kerusakan tambalan dan lubang, serta nilai IKP untuk masing masing unit penelitian dapat diketahui kualitas perkerasan beragam, dari tingkat Sangat Parah, Parah, Sedang, Baik, hingga Sangat Baik. Hasil rata-rata nilai IKP Jalan Daan Mogot arah Tangerang dari KM +14,000 s/d KM+16,500 adalah 87,09 dengan kelas kondisi Sangat Baik.
\end{abstract}

Kata Kunci: Jalan Daan Mogot; kerusakan jalan dan Indeks Kondisi Perkerasan

\section{PENDAHULUAN}

Jalan Daan Mogot adalah nama salah satu jalan utama Jakarta. Nama jalan ini diambil dari nama seorang pejuang dan pelatih anggota PETA yaitu Daan Mogot. Jalan ini membentang sepanjang 27,5 KM dari Sukarasa,Tangerang, sampai dengan Grogol. Jalan ini merupakan bagian dari Jalan Nasional Rute Satu (1) (Permana, 2020). Kendaraan yang melintas di Jalan Daan Mogot sering mengalami banyak hambatan, dikarenakan kondisi jalan yang mengalami banyak kerusakan, sehingga terjadi penambahan waktu tempuh saat perjalanan. Volume kendaraan berat maupun ringan yang melintas di jalan tersebut sangat tinggi, hal ini dikarenakan Jalan Daan Mogot merupakan salah satu Jalan Nasional non tol yang menghubungkan kota Jakarta dengan Tangerang maupun Merak. Hal tersebut menjadikan jalan ini sangat padat oleh kendaraan pribadi yang menuju dan berasal dari lokasi kerja di pusat kota, serta kendaraan niaga yang 
mengangkut beban logistik. Dalam rangka meningkatkan dan mengembangkan kinerja jalan untuk menjamin kualitas perkerasan jalan, maka diperlukan pendekatan metode perbaikan jalan dengan data yang ada.

Menurut TPGJAK (Departemen Pekerjaan Umum Direktorat Jendral Bina Marga, 1997), klasifikasi jalan terbagi menjadi :

a) Klasifikasi menurut fungsi jalan yaitu terbagi atas, pertama adalah Jalan Arteri yang merupakan jalan yang melayani angkutan utama dengan ciri-cirinya seperti perjalanan jarak jauh, kecepatan rata-rata tinggi, dan jumlah jalan masuk dibatasi secara efisien. Kedua adalah Jalan Kolektor yang merupakan jalan yang melayani angkutan pengumpul/pembagi dengan ciri-ciri perjalanan jarak sedang, kecepatan rata-rata sedang dan jumlah jalan masuk dibatasi. Ketiga adalah Jalan Lokal yang merupakan jalan yang melayani angkutan setempat dengan ciri-ciri perjalanan jarak dekat, kecepatan rata-rata rendah, dan jumlah jalan masuk tidak dibatasi.

b) Klasifikasi menurut kelas jalan Pada SNI tentang Teknik Perencanaan Geometrik Jalan Antar Kota 1997, kelas jalan dijelaskan dalam Tabel 1.

Tabel 1 Klasifikasi menurut kelas jalan

\begin{tabular}{ccc}
\hline Klasifikasi fungsi & Kelas & $\begin{array}{c}\text { Muatan Sumbu Terberat MST } \\
\text { (ton) }\end{array}$ \\
\hline Arteri & I & $>10$ \\
& II & 10 \\
& III A & 8 \\
\hline Kolektor & III A & 8 \\
& III B & 8 \\
\hline
\end{tabular}

(Sumber: Teknik Perencanaan Geometrik Jalan Antar Kota 1997; 4)

c) Klasifikasi menurut medan jalan

1. Medan jalan diklasifikasikan berdasarkan kondisi sebgaian besar kemiringan medan yang diukur tegak lurus kontur.

2. Klasifikasi menurut medan jalan untuk perencanaan geometrik dapat dilihat pada Tabel 2

Tabel 2 Golongan medan

\begin{tabular}{ccc}
\hline Golongan Medan & Notasi & $\begin{array}{c}\text { Kemiringan Medan } \\
(\%)\end{array}$ \\
\hline Datar & D & $<3$ \\
Perbukitan & B & $3-25$ \\
Pegunungan & G & $>25$ \\
\hline
\end{tabular}

(Sumber: Teknik Perencanaan Geometrik Jalan Antar Kota 1997; 5)

d) Klasifikasi menurut PP. No 34/2006 pasal 25 adalah jalan Nasional, jalan Provinsi, jalan Kabupaten, jalan Kota dan jalan Desa

1. Dalam pasal 26 disebutkan, Jalan Nasional yang terdiri atas jalan arteri primer; jalan kolektor primer yang menghubungkan antar ibukota provinsi; jalan tol; dan jalan strategis nasional.

2. Dalam pasal 27 disebutkan, Jalan provinsi yang terdiri atas jalan kolektor primer yang menghubungkan ibukota provinsi dengan ibukota kabupaten atau kota; jalan kolektor primer yang menghubungkan antaribukota kabupaten atau kota; jalan strategis provinsi; dan jalan di Daerah Khusus Ibukota Jakarta, kecuali jalan sebagaimana dimaksud dalam Pasal 26.

3. Dalam pasal 28 disebutkan, Jalan kabupaten yang terdiri atas jalan kolektor primer yang tidak termasuk jalan nasional sebagaimana dimaksud dalam Pasal 26 huruf b dan jalan provinsi sebagaimana dimaksud dalam Pasal 27; jalan lokal primer yang menghubungkan ibukota kabupaten dengan ibukota kecamatan, ibukota kabupaten dengan pusat desa, antar ibukota kecamatan, ibukota kecamatan dengan desa, dan 
antardesa; jalan sekunder yang tidak termasuk jalan provinsi sebagaimana dimaksud dalam Pasal 27; dan jalan strategis kabupaten.

4. Dalam pasal 29 disebutkan, Jalan kota sebagaimana dimaksud dalam Pasal 25 huruf d adalah jalan umum pada jaringan jalan sekunder di dalam kota.

\section{Perkerasan jalan lentur}

Menurut International Research Journal of Engineering and Technology (Neeraj Syal, 2019) yang dimaksud dengan perkerasan lentur (flexible pavement) adalah perkerasan jalan yang terdiri dari campuran material aspal atau bitumen dan agregat ditempatkan pada kualitas yang baik dan bahan granular yang dipadatkan. Perkerasan lentur sering digunakan untuk jalan yang didesain menerima beban ringan hingga sedang, seperti jalan dalam kota.

\section{METODE PENELITIAN}

Data yang diperoleh dari penelitian ini adalah data yang diambil dari survei kondisi perkerasan menggunakan Google Streetview. Dalam proses pengumpulan data, sampel yang diambil adalah semua data yang berkaitan dengan perkerasan jalan Daan Mogot.

Penelitian ini berlokasi di Jalan Daan Mogot yang berstatus Jalan Nasional dengan kode ruas 2000111. Jalan ini terdiri dari 4 lajur 2 arah yang menghubungkan Jakarta dengan Tangerang.

Dari data yang didapatkan, maka data tersebut akan diperhitungkan kedalam metode yang ada dengan menggunakan beberapa rumus dan hasil visual dari Google Streetview. Hasil visual dari Google Streetview diolah menjadi data untuk perhitungan IKP, seperti tingkat keparahan kerusakan serta kuantitas kerusakan. Selanjutnya dihitung nilai kerapatan untuk mencari nilai pengurang yang menggunakan kurva hubungan nilai kerapatan dengan nilai pengurang. Selanjutnya nilai pengurang yang ada direduksi dan ditotal menjadi nilai pengurang total. Nilai pengurang total dimasukan dalam kurva hubungan nilai pengurang total dengan nilai pengurang terkoreksi. Selanjutnya nilai pengurang terkoreksi dipakai menjadi nilai pengurang IKP, sehinnga didapatkan nilai IKP pada ruas tersebut. Setelah mendapatkan hasil nilai IKP dilakukan investigasi kerusakan di 3 tahun terakhir. Hal ini dilakukan untuk mengetahui keparahan kerusakan dan penyebab kerusakan tersebut.

\section{Metode Indeks Kondisi Perkerasan (IKP)}

Indeks Kondisi perkerasan (IKP) adalah salah satu indikator untuk menilai kondisi perkerasan yang mempunyai rentang nilai mulai dari 0 hingga 100, dari 0 yang berarti kondisi perkerasan paling jelek yang bisa saja terjadi dan nilai 100 yang berarti kondisi perkerasan terbaik, seperti yang diilustrasikan pada Gambar 1.

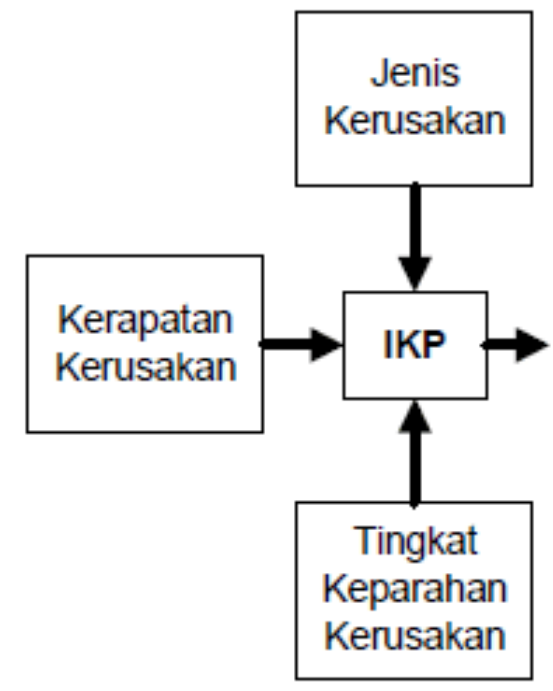

a. Prinsip penentuan IKP

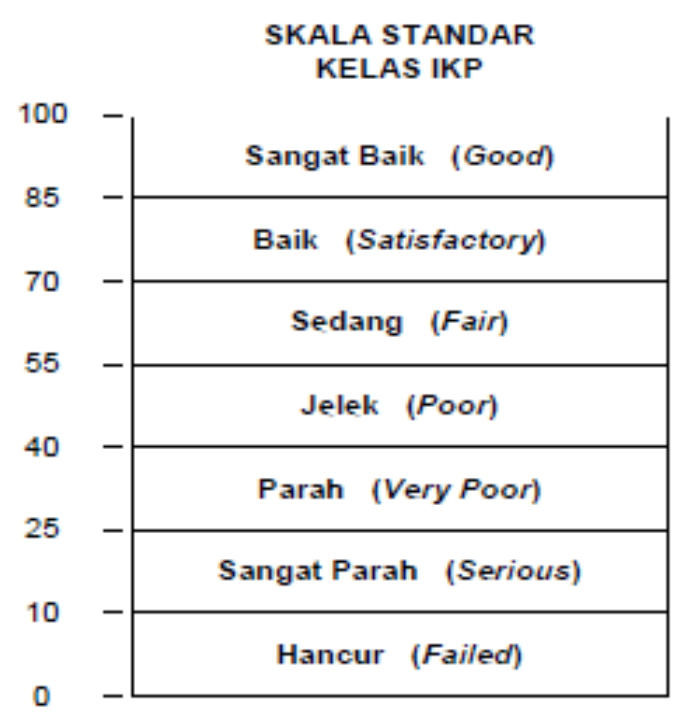

b. Hubungan IKP dengan kelas kondisi

Gambar 1 Skala kelas indeks kondisi perkerasan (Kementrian Pekerjaan Umum dan Perumahan Rakyat, 2016) 
Untuk menentukan tingkat kerusakan, maka kenyamanan dijadikan faktor penentu, petugas survei menggunakan kendaraan yang dijalankan pada kecepatan normal (30-40) km/jam dan kemudian menggunakan batasan tingkat keparahan kenyamanan yang diuraikan di bawah (Kementrian Pekerjaan Umum dan Perumahan Rakyat, 2016).

a) Rendah (R) - Kendaraan terasa mengalami getaran sehingga kecepatan kendaraan tidak perlu dikurangi.

b) Sedang (S) - Kendaraan sangat bergetar sehingga kecepatan kendaraan perlu dikurangi.

c) Tinggi (T) - Kendaraan sangat terguncang sehingga kendaraan harus diperlambat.

\section{HASIL DAN PEMBAHASAN}

Pengambilan data visual menggunakan Google Earth Pro. Jalan sepanjang 2,5 KM ini dibagi menjadi 25 stasiun, dengan jarak per stasiun sepanjang $100 \mathrm{~m}$. Dalam satu stasiun dibagi lagi menjadi dua unit perkerasan, dengan jarak per unit sepanjang $50 \mathrm{~m}$ per lajur. Jumlah unit perkerasan yang ditinjau adalah 100 unit perkerasan. Berikut adalah Gambar 2 Peta lokasi stasiun Jalaan Daan Mogot.

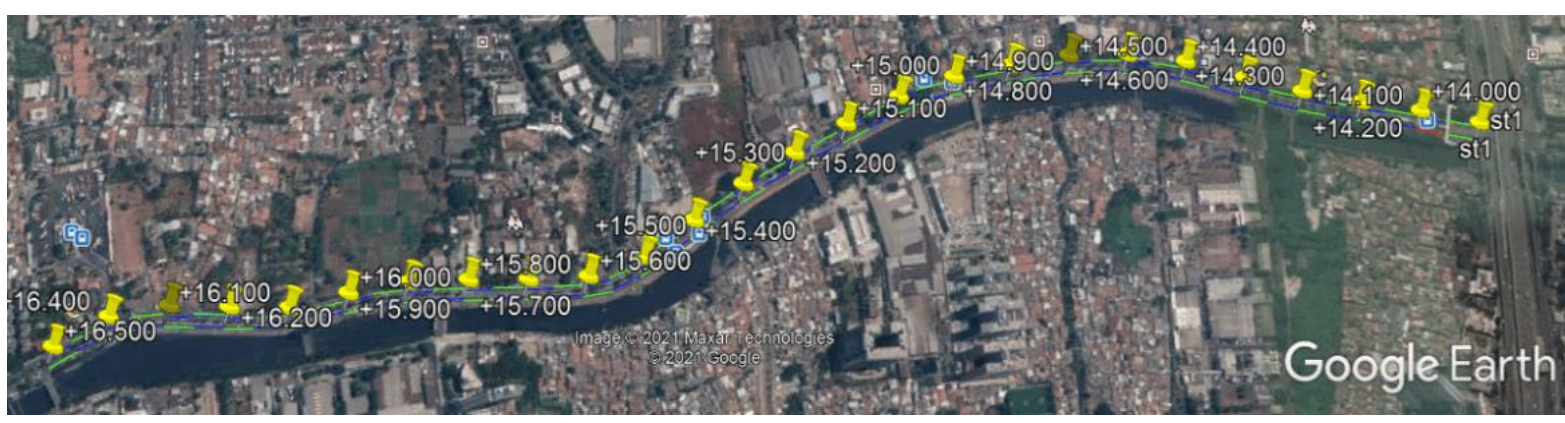

Gambar 2 Peta lokasi stasiun Jalan Daan Mogot

Dari hasil pengamatan visual tahun 2020 menunjukan bahwa kerusakan pada Jalan Daan Mogot terdiri dari Retak Kulit Buaya, Kegemukan (Bleeding), Keriting, Depresi/Amblas, Retak Memanjang \& Melintang, Tambalan/Galian Utilitas, Lubang, dan Sungkur. Berikut adalah Tabel 3 Persentase kerusakan Jalan Daan Mogot satuan $\mathrm{m}^{2}$ :

Tabel 3 Persentase kerusakan Jalan Daan Mogot satuan $\mathrm{m}^{2}$

\begin{tabular}{|c|c|c|}
\hline Jenis Kerusakan & Tingkat & $\%$ \\
\hline Retak Kulit Buaya & Tinggi & 0,65014 \\
\hline \multirow{2}{*}{ Kegemukan } & Sedang & 2,46414 \\
\hline & Tinggi & 0,08455 \\
\hline Keriting & Sedang & 0,5321 \\
\hline Depresi/Amblas & Tinggi & 1,19727 \\
\hline \multirow{2}{*}{ Retak Memanjang \& Melintang } & Sedang & 0,27041 \\
\hline & Tinggi & 0,03091 \\
\hline \multirow{3}{*}{ Tambalan/Galian Utilitas } & Rendah & 62,7337 \\
\hline & Sedang & 20,3651 \\
\hline & Tinggi & 9,74393 \\
\hline \multirow{3}{*}{ Lubang } & Rendah & 0,07731 \\
\hline & Sedang & 0,13376 \\
\hline & Tinggi & 1,23832 \\
\hline Sungkur & Sedang & 0,47832 \\
\hline & Total \% & 100 \\
\hline
\end{tabular}

Dapat disimpulkan dari tabel 3 kerusakan terbanyak pada Tambalan. Pada kerusakan Tambalan tingkat Sedang dan Tinggi, terdapat kerusakan lain pada tambalan tersebut, seperti Retak Kulit Buaya serta Lubang. Berikut adalah Tabel 4 Persentase kerusakan Jalan Daan Mogot: 
Tabel 4 Persentase kerusakan Jalan Daan Mogot

\begin{tabular}{cccc}
\hline Jenis Kerusakan & Tingkat & Jumlah & $\%$ \\
\hline Retak Kulit Buaya & Tinggi & 13 & 10,2362 \\
\hline Kegemukan & Sedang & 4 & 3,14961 \\
\cline { 2 - 4 } Keriting & Tinggi & 1 & 0,7874 \\
\hline Depresi/Amblas & Sedang & 5 & 3,93701 \\
\hline \multirow{2}{*}{ Retak Memanjang \& Melintang } & Tinggi & 3 & 2,3622 \\
\hline \multirow{2}{*}{ Tambalan/Galian Utilitas } & Sedang & 20 & 15,748 \\
\cline { 2 - 4 } & Tinggi & 1 & 0,7874 \\
\hline \multirow{2}{*}{ Lubang } & Rendah & 7 & 5,51181 \\
\cline { 2 - 4 } & Sedang & 17 & 13,3858 \\
\cline { 2 - 4 } & Tinggi & 14 & 11,0236 \\
\hline Sungkur & Rendah & 22 & 17,3228 \\
\cline { 2 - 4 } & Sedang & 7 & 5,51181 \\
\cline { 2 - 4 } & Tinggi & 9 & 7,08661 \\
\hline & Sedang & 4 & 3,14961 \\
\hline & Total & 127 & 100 \\
\cline { 2 - 4 } & &
\end{tabular}

Dapat disimpulkan dari tabel 4 kerusakan terbanyak pada kerusakan Lubang sebanyak 38 unit serta kerusakan Tambalan/Galian Utilitas sebanyak 38 unit. Kerusakan terkecil pada kerusakan Depresi/Amblas sebanyak 3 unit.

\section{Metode Indeks Kondisi Perkerasan}

Luasan unit yang dibolehkan dalam pedoman Indeks Kondisi Perkerasan adalah $225 \pm 90 \mathrm{~m}^{2}$, sedangkan luas unit perkerasan Jalan Daan Mogot dengan lebar 3,5 m per lajur dan panjang $50 \mathrm{~m}$ per unit, adalah $175 \mathrm{~m}^{2}$. Luas unit Jalan Daan Mogot sudah memenuhi standar pedoman Indeks Kondisi Perkerasan, dengan total 100 unit di sepanjang 2,5 KM. Berikut adalah Gambar 3 Pembagian ruas perkerasan menajdi unit sampel:

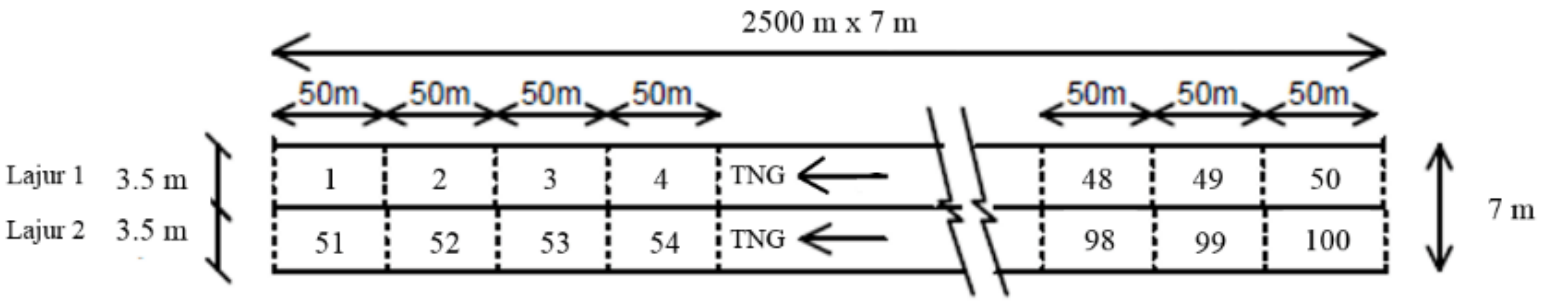

Gambar 3 Pembagian ruas perkerasan menjadi unit sampel

(Sumber: Pedoman Indeks Kondisi Perkerasan, Kementrian PUPR)

Pada Gambar 3 menggambarkan satu unit sampel memiliki lebar 3,5 meter dengan panjang 50 meter per sampel. Dengan panjang 2,5 KM dan dua lajur membuat total sampel menjadi 100 unit sampel.

Sesuai pedoman Indeks Kondisi Perkerasan unit sampel Jalan Daan Mogot lebih dari 40 yaitu 100 unit sampel, jumlah minimum unit sampel yang harus di survei adalah 10\% dari 100 unit. Dalam survei ini digunakan seluruh sampel atau 100 unit sampel, demi mendapatkan hasil yang maksimal.

Langkah Selanjutnya adalah mencatat dan mengukur luas kerusakan yang ada di setiap unit sampel. Gambar 4 merupakan formulir Indeks Kondisi Perkerasan Jalan Daan Mogot arah Tangerang KM +14,750 - +14,800. 


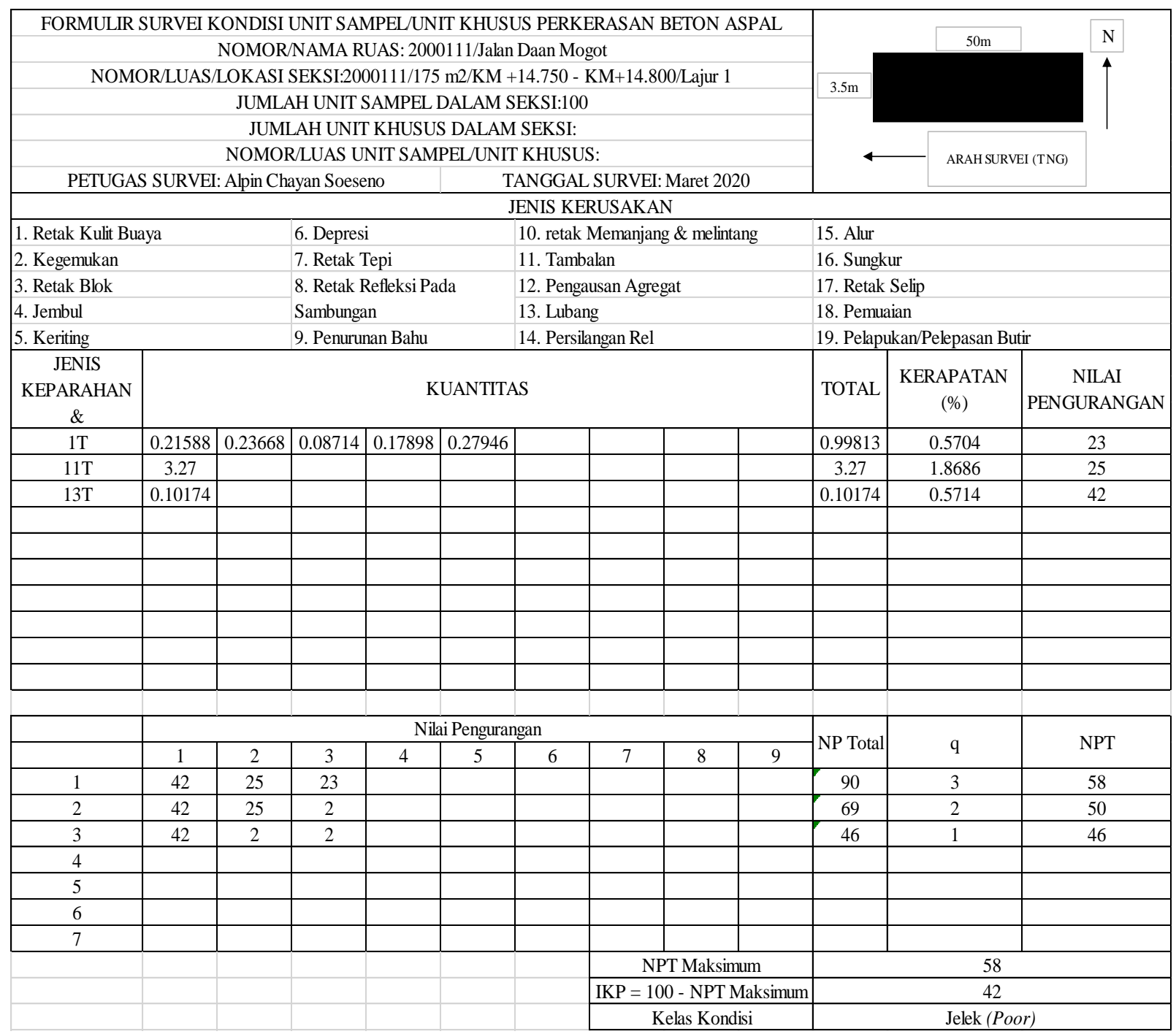

Gambar 4 Formulir IKP KM +14,750 - +14,800

a) Menghitung Kuantitas masing-masing jenis kerusakan pada sta. $+14,750 \mathrm{~s} / \mathrm{d}$ sta. $+14,800=$
1. Retak Kulit Buaya(T)
$=(0,21588+0,23668+0,08714+0,17898+0,27946)$
$=0,99813 \mathrm{~m}^{2}$
2. Tambalan(T)
$=3,27$
$=3,27 \mathrm{~m}^{2}$
3. Lubang(T)
$=0,10174$
$=0,10174 \mathrm{~m}^{2}$

b) Menghitung Kerapatan masing-masing jenis kerusakan pada sta. $+14,750 \mathrm{~s} / \mathrm{d}$ sta. $+14,800=$

1. Retak Kulit Buaya $=\frac{\text { Luas total kerusakan }}{\text { Luas total unit sampel }} \times 100$

$$
\begin{aligned}
& =\frac{0,99813 \mathrm{~m} 2}{3,5 \mathrm{~m} 2 \times 50 \mathrm{~m} 2} \times 100 \\
& =0,5704 \%
\end{aligned}
$$

2. Tambalan

$$
\begin{aligned}
& =\frac{\text { Luas total kerusakan }}{\text { Luas total unit sampel }} \times 100 \\
& =\frac{3,27 \mathrm{~m} 2}{3,5 \mathrm{~m} 2 \times 50 \mathrm{~m} 2} \times 100 \\
& =1,8686 \%
\end{aligned}
$$


3. Lubang

$$
\begin{aligned}
& =\frac{\text { Jumlah lubang kerusakan }}{\text { Luas total unit sampel }} \times 100 \\
& =\frac{1 \text { buah }}{3,5 \mathrm{~m} 2 \times 50 \mathrm{~m} 2} \times 100 \\
& =0,5714 \%
\end{aligned}
$$

c) Mencari Nilai Pengurangan masing masing jenis kerusakan menggunakan kurva hubungan nilai pengurang dan kerapatan kerusakan menggunakan kurva pada Gambar 5.

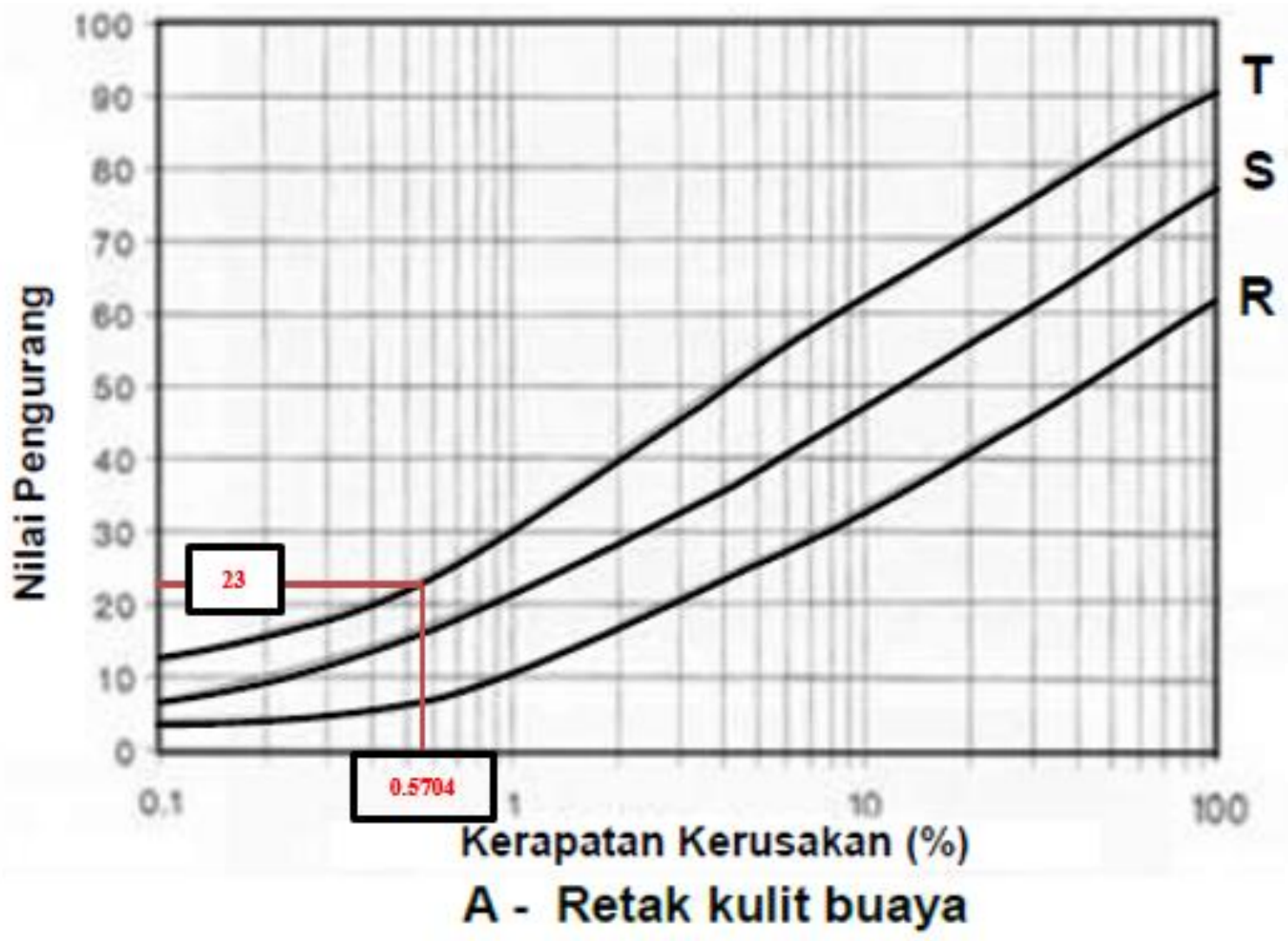

Gambar 5 Kurva nilai pengurang retak kulit buaya

Dari hasil perhitungan kerapatan di dapatkan hasil 0,5704, angka tersebut di masukkan ke kurva diatas dan tarik garis tegak lurus vertikal ke atas hingga bertemu garis kurva tingkat Tinggi (T). Setelah itu tarik garis tegak lurus horizontal ke kiri hingga mendapatkan angka di 23. Nilai Pengurang kerusakan Retak Kulit Buaya dengan nilai kerapatan 0,5704 dan tingkat kerusakan Tinggi adalah 23. Untuk kerusakan Tambalan digunakan Kurva Nilai Pengurang Tambalan dan Galian Utilitas,dan untuk kerusakan Lubang digunakan Kurva Nilai Pengurang Lubang (satuan metrik).

d) Nilai Pengurang Terkoreksi (NPT) diperoleh dari kurva hubungan antara Nilai Pengurang total dengan jumlah individu Nilai Pengurang yang lebih besar dari 2 (q), sedangkan NPT maksimum ditentukan melalui prosedur yang diuraikan di bawah.

1. Susun Nilai-nilai Pengurang dalam urutan mulai dari nilai terbesar sampai nilai yang terkecil.

2. Tentukan jumlah maksimum individu Nilai-nilai Pengurang yang diijinkan $(m)$, dengan menggunakan Persamaan dibawah.

$$
m=1+\frac{9}{98}(100-N P \text { maksimum }) \leq 10
$$

Untuk Gambar 4: $m=1+\frac{9}{98}(100-42)=6,3 \leq 10$ 
Pada persamaan di atas, $m$ adalah jumlah individu nilai-nilai pengurang yang diijinkan termasuk pecahan (harus lebih kecil atau sama dengan sepuluh). Np maksimum adalah nilai pengurang terbesar.

Reduksi jumlah individu Nilai Pengurang menjadi m buah, termasuk bagian pecahannya, dan lakukan koreksi NP terakhir. Apabila jumlah individu Nilai-nilai Pengurang lebih kecil dari m, maka semua Nilai Pengurang digunakan pada proses penentuan NPT maksimum.

e) Tentukan NPT maksimum dengan cara iterasi sebagai berikut. Pertama tentukan Nilai Pengurang total dengan menjumlahkan Nilai-nilai Pengurang semua kerusakan pada unit sampel. Selanjutnya tentukan q sebagai jumlah individu Nilai-nilai Pengurang yang lebih besar dari 2,0. Selanjutnya tentukan Nilai Pengurang Terkoreksi (NPT) dengan cara mengoreksi Nilai Pengurang total oleh q. Koreksi dilakukan dengan menggunakan kurva yang ditunjukkan pada Gambar 6. Selanjutnya reduksi Nilai Pengurang terkecil yang lebih besar dari 2,0 menjadi 2,0 dan ulangi langkah-langkah di atas, sampai $\mathrm{q}=1$. Terakhir tentukan NPT maksimum dari nilai-nilai yang diperoleh melalui langkah langkah iterasi di atas.

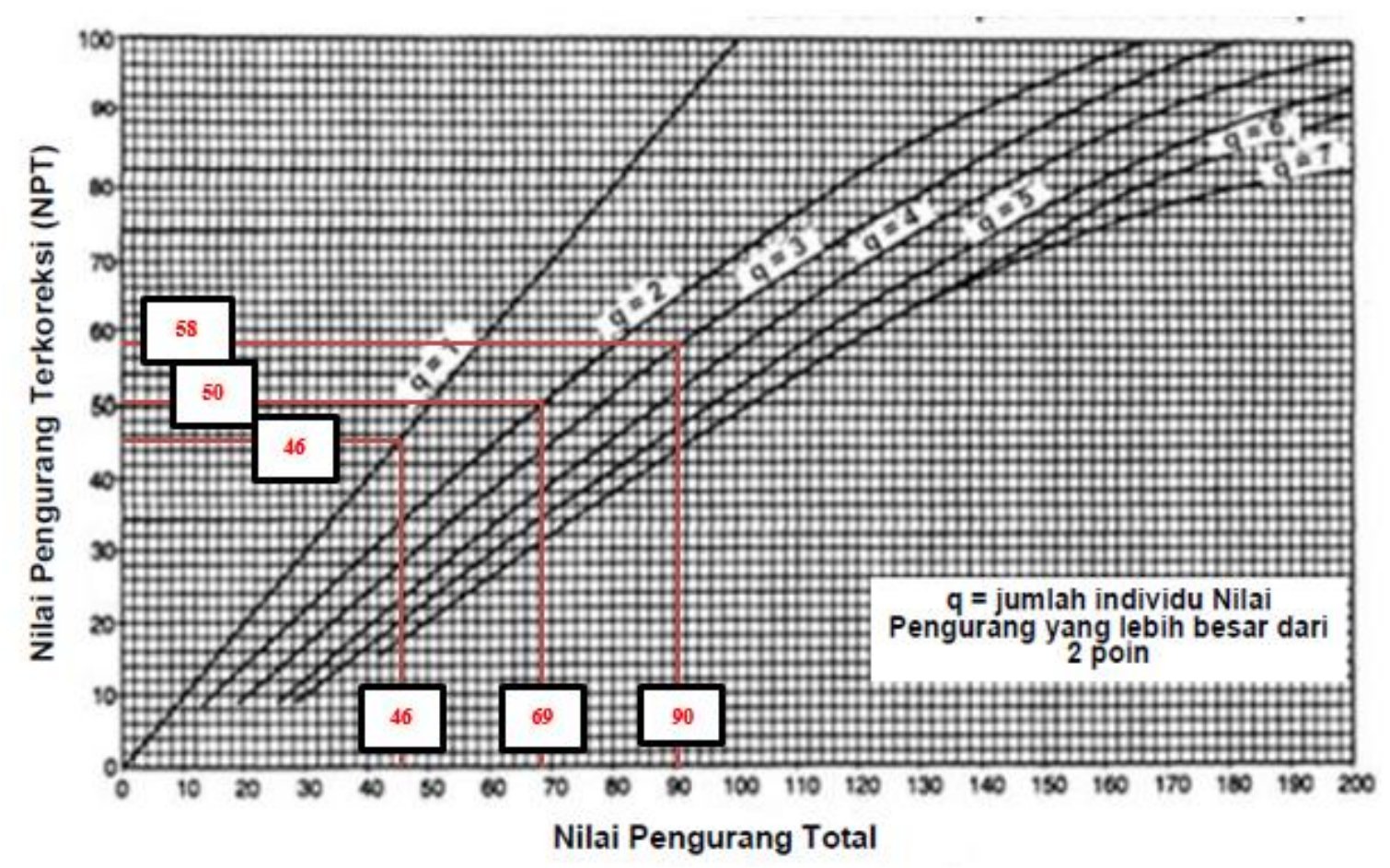

Gambar 6 Kurva untuk menentukan Nilai Pengurang Terkoreksi (NPT) unit sampel perkerasan beton aspal

Setelah mendapatkan hasil NP total 90 di q3, angka tersebut di masukkan ke kurva dan tarik garis tegak lurus vertikal ke atas hingga bertemu garis kurva $\mathrm{q}=3$. Setelah itu tarik garis tegak lurus horizontal ke kiri hingga mendapatkan angka di 58. Untuk q2 menggunakan garis kurva q=2, dan q1 menggunakan garis kurva q=1. Hasil Nilai Pengurang Terkoreksi tertinggi adalah 58 pada q3.

f) Penghitungan IKP unit sampel

Setelah NPT maksimum diperoleh, IKP setiap unit sampel dihitung dengan rumus sebagai berikut:

$$
\text { IKP }=100-\text { NPTmaksimum }
$$

Untuk Gambar $4 I K P=100-58=42$ Jelek (poor)

IKP adalah Indeks Kondisi Perkerasan unit sampel perkerasan beton aspal. NPT maksimum adalah Nilai Pengurang Terkoreksi terbesar unit sampel perkerasan beton aspal.

Berikut adalah Gambar 7 Persentase Nilai IKP Jalan daan Mogot arah Tangerang dari KM +14,000 s/d KM+16,500: 


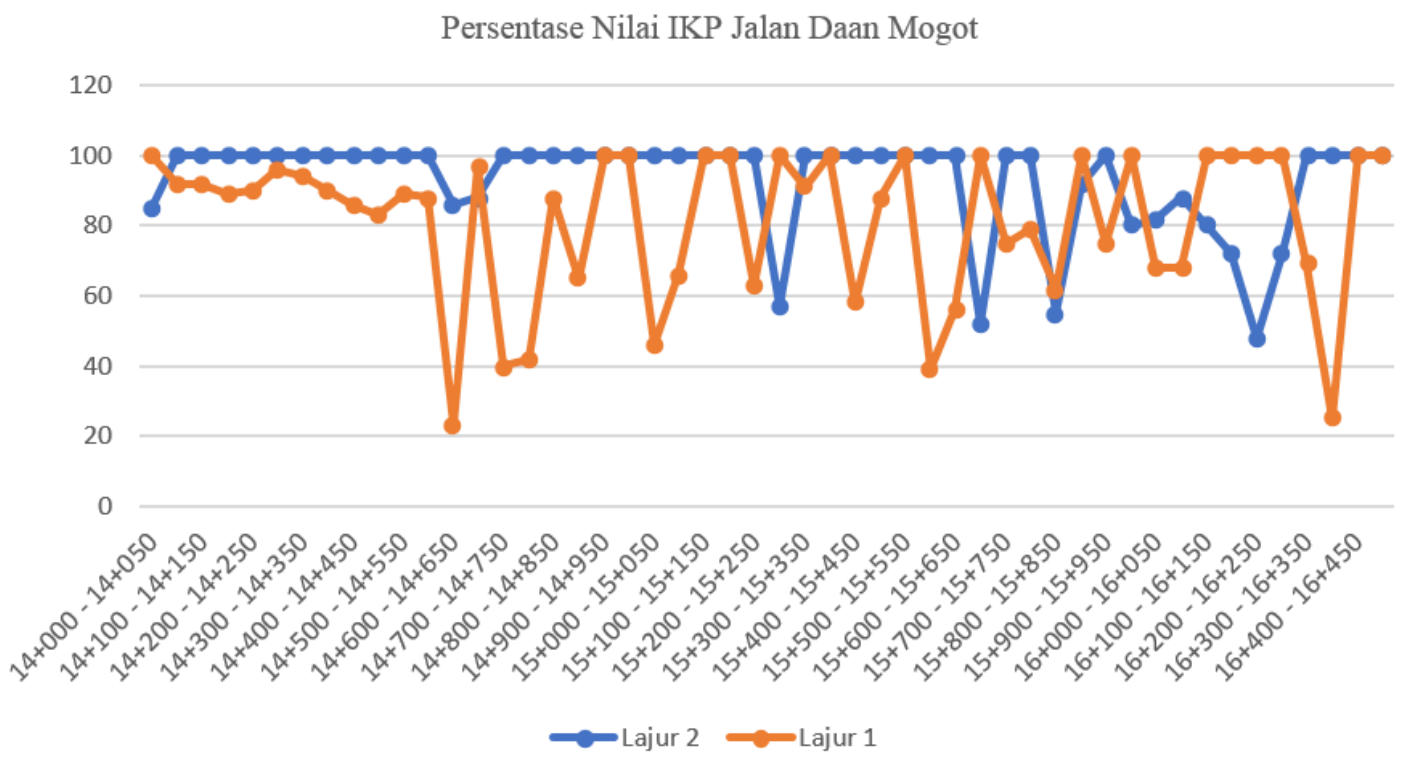

Gambar 7 Persentase nilai IKP Jalan Daan Mogot

Dari nilai IKP untuk masing masing unit penelitian dapat diketahui kualitas perkerasan beragam, dari tingkat Parah (Very Poor), Parah (Poor), Sedang (Fair), Baik (Satisfactory), hingga Sangat Baik (Good). Hasil rata-rata nilai IKP Jalan Daan Mogot arah Tangerang dari KM +14,000 s/d KM+16,500 adalah 87,09 dengan kelas kondisi Sangat Baik (Good).

\section{Investigasi kerusakan serta penanganan}

Dalam pedoman IKP terdapat standar untuk menentukan jenis penanganan berdasarkan hasil dari nilai IKP per unit sampel. Berikut adalah Tabel 5 Penggunaan IKP dalam menentukan jenis penanganan.

Tabel 5 Penggunaan IKP dalam menentukan jenis penanganan

\begin{tabular}{cc}
\hline IKP & Jenis Penanganan \\
\hline$\geq 85$ & Pemeliharaan rutin \\
$70-85$ & Pemeliharaan berkala \\
$55-70$ & Peningkatan struktural \\
$<55$ & Rekonstrusi/daur ulang
\end{tabular}

(Sumber:Pedoman Indeks Kondisi Perkerasan, Kementrian PUPR)

a) Pemeliharaan Rutin adalah penanganan yang diberikan hanya terhadap lapis permukaan yang sifatnya untuk meningkatkan kualitas berkendaraan (Riding Quality), tanpa meningkatkan kekuatan struktural, dan dilakukan sepanjang tahun.

b) Pemeliharaan berkala jalan adalah kegiatan penanganan pencegahan terjadinya kerusakan yang lebih luas dan setiap kerusakan yang diperhitungkan dalam desain agar penurunan kondisi jalan dapat dikembalikan pada kondisi kemantapan sesuai dengan rencana.

c) Peningkatan struktur merupakan kegiatan penanganan untuk dapat meningkatkan kemampuan ruas-ruas jalan dalam kondisi tidak mantap atau kritis agar ruas-ruas jalan tersebut sesuai dengan umur rencana yang ditetapkan.

d) Rekonstruksi jalan adalah peningkatan struktur yang merupakan kegiatan penanganan untuk dapat meningkatkan kemampuan bagian ruas jalan yang dalam kondisi rusak berat agar bagian jalan tersebut mempunyai kondisi mantap kembali sesuai dengan umur rencana yang ditetapkan 


\section{Metode perbaikan Bina Marga}

Penanganan kerusakan jalan pada lapisan lentur menggunakan metode perbaikan standar untuk pemeliharaan rutin jalan (Kementrian Pekerjaan Umum Direktorat Jenderal Bina Marga, 2011). Jenis-jenis metode penanganan tiap-tiap kerusakan adalah :

a) Metode Perbaikan P1 (Penebaran Pasir)

Jenis kerusakan yang diperbaiki adalah kegemukan aspal terutama pada tikungan dan tanjakan. Langkah penanganannya adalah pertama memobilisasi peralatan, pekerja dan material ke lapangan. Selanjutnya memberikan tanda pada jalan yang akan diperbaiki. Selanjutnya membersihkan daerah dengan air compressor. Menebarkan pasir kasar atau agregat halus (tebal $>10 \mathrm{~mm}$ ) di atas permukaan yang terpengaruh kerusakan. Terakhir melakukan pemadatan dengan baby roller.

b) Metode Perbaikan P2 (Pelaburan Aspal Setempat)

Jenis kerusakan yang ditangani adalah kerusakan tepi bahu jalan beraspal, Retak buaya $<2 \mathrm{~mm}$, Retak garis lebar < $2 \mathrm{~mm}$, dan terkelupas. Langkah penanganannya adalah pertama memobilisasi peralatan, pekerja dan material ke lapangan. Selanjutnya membersihkan bagian yang akan ditangani dengan air compressor, permukaan jalan harus bersih dan kering. Selanjutnya menyemprotkan dengan aspal emulsi sebanyak 1,5 liter/m2 dan untuk cut back 1 liter/ $\mathrm{m}^{2}$. Selanjutnya menebarkan pasir kasar atau agregat halus $5 \mathrm{~mm}$ hingga rata. Terakhir melakukan pemadatan dengan baby roller (minimum 3 lintasan).

c) Metode Perbaikan P3 (Pelapisan Retakan)

Jenis kerusakan yang ditangani adalah lokasi-lokasi retak satu arah dengan lebar retakan $<2$ mm. Langkah penanganannya adalah pertama memobilisasi peralatan, pekerja dan material ke lapangan. Selanjutnya membersihkan bagian yang akan ditangani dengan air compressor, sehingga permukaan jalan bersih dan kering. Selanjutnya aduk aspal emulsi dan pasir kasar dengan menggunakan Concrete Mixer dengan komposisi sebagai berikut, Pasir 20 liter dan Aspal emulsi 6 liter.Selanjutnya menyemprotkan tack coat (0,2 liter/ m2 di daerah yang akan di perbaiki). Selanjutnya menebar dan meratakan campuran aspal pada seluruh daerah yang telah diberi tanda. Terakhir melakukan pemadatan dengan baby roller.

d) Metode Perbaikan P4 (Pengisian Retak)

Jenis kerusakan yang ditangani adalah lokasi-lokasi retak satu arah dengan lebar retakan > 2 mm. Langkah penanganannya adalah pertama memobilisasi peralatan, pekerja dan material ke lapangan. Selanjutnya membersihkan bagian yang akan ditangani dengan air compressor, sehingga permukaan jalan bersih dan kering. Selanjutnya mengisi retakan dengan aspal emulsi 2 liter/ $\mathrm{m}^{2}$ menggunakan aspal sprayer. Selanjutnya menebarkan pasir kasar pada retakan yang telah diisi aspal (tebal $10 \mathrm{~mm}$ ). Terakhir memadatkan minimal 3 lintasan dengan baby roller.

e) Metode Perbaikan P5 (Penambalan Lubang)

Jenis kerusakan yang ditangani adalah Lubang kedalaman $>50 \mathrm{~mm}$, Keriting kedalaman > $30 \mathrm{~mm}$, Alur kedalaman $>30 \mathrm{~mm}$, Ambles kedalaman > $50 \mathrm{~mm}$, Jembul kedalaman > $50 \mathrm{~mm}$, Kerusakan tepi perkerasan jalan, dan Retak buaya lebar $>2 \mathrm{~mm}$. Langkah penanganannya adalah pertama gali material pondasi jalan hingga lapisan keras (biasanya kedalaman perkerasan jalan 150-200 mm, harus dibobok/digali). Selanjutnya periksa kadar air optimum material perkerasan jalan yang ada. Jika kering tambahkan air hingga keadaan optimum (OMC), jika basah gali material dan biarkan sampai kering. Selanjutnya gunakan Vibrating Hammer untuk memadatkan material lapisan dasar yang ada. Selanjutnya tambahkan agregat kelas "A" dengan ketebalan max 100 mm dalam keadaan OMC.Selanjutnya padatkan tiap lapis agregat klas "A” sampai $40 \mathrm{~mm}$ dibawah permukaan, dengan Vibrating Plate Temper. Selanjutnya menyemprotkan lapis Prime Coat dengan menggunakan aspal Sprayer $\left(0,5 \mathrm{~L} / \mathrm{m}^{2}\right.$ untuk "cut back” atau $0,8 \mathrm{~L} / \mathrm{m}^{2}$ untuk aspal emulsi). Selanjutnya menebarkan dan memadatkan campuran aspal sampai diperoleh permukaan yang rata. Terakhir memadatkan dengan baby roller (minimum 5 lintasan)

f) Metode Perbaikan P6 (Perataan)

Jenis kerusakan yang ditangani adalah lokasi keriting dengan kedalaman $<30 \mathrm{~mm}$, lokasi lubang dengan kedalaman $<50 \mathrm{~mm}$, lokasi alur dengan kedalaman $<30 \mathrm{~mm}$, lokasi terjadinya penurunan dengan kedalaman $<50 \mathrm{~mm}$, dan lokasi jembul dengan kedalaman < $50 \mathrm{~mm}$. Langkah penanganannya adalah pertama membersihkan bagian yang akan ditangani dengan tenaga manusia. Selanjutnya melaburkan tack coat 0,5 liter $/ \mathrm{m} 2$. Selanjutnya menaburkan campuran aspal kemudian memadatkannya sampai diperoleh permukaan yang rata. Terakhir memadatkan dengan baby roller (minimum 5 lintasan). 


\section{Evaluasi penanganan kerusakan dalam 3 tahun terakhir}

Dari hasil IKP Jalan Daan Mogot KM $+14,000$ s/d $+16,500$, nilai IKP unit sampel yang di bawah $\leq 85$ akan diinvestigasi kerusakan nya dengan cara pengecekan visual tahun sebelumnya. Hal ini dilakukan untuk mengetahui riwayat kerusakan unit sampel tersebut, dan melihat penanganan yang dilakukan pada kerusakan tersebut sudah tepat atau belum dengan kondisi kerusakan yang ada.

a) Kerusakan $\mathrm{KM}+14,600$

$\mathrm{KM}+14,600$ berada di sebelah sungai yang menghubungkan sungai Ciliwung (Jakarta) dengan sungai Cisadane (Tangerang). Hasil nilai IKP KM ini adalah 23 (Sangat Parah, Serious) untuk Lajur 1. Berikut adalah kondisi kerusakaan pada tahun 2020. Dari hasil penelitian terlihat ada sebuah tambalan dengan panjang \pm 10 meter dan lebar \pm 2 meter. Tambalan tersebut memiliki 3 buah lubang tingkat Sedang yang dapat membuat tapak ban kendaraan kecil hingga besar dapat masuk ke lubang tersebut. Kerusakan ini sangat mengganggu kenyamanan berkendara dan menghambat laju kendaraan, karena harus mengurangi kecepatan saat melewati kerusakan tersebut.

Selanjutnya pengecekan di tahun 2019, untuk mengetahui kondisi kerusakan sebelum di tambal sesuai dengan kondisi 2020. Berikut adalah kondisi kerusakan pada tahun 2019. Dari hasil penelitian terlihat bahwa dimensi tambalan lebih kecil dan berbeda dengan tahun 2020, dengan kerusakan gelombang serta lubang tingkat Rendah hingga Sedang. Dapat disimpulkan bahwa kerusakan pada tahun 2019 sudah diperbaiki, namun pada tahun 2020 perbaikan nya sudah mengalami kerusakan lagi.

Selanjutnya pengecekan di tahun 2018, untuk mengetahui kondisi kerusakan sebelum di tambal sesuai dengan kondisi 2019. Berikut adalah kondisi kerusakan pada tahun 2018. Dari hasil penelitian terlihat bahwa hanya ada 2 tambalan dengan dimensi tambalan panjang dan lebar $\pm 30 \mathrm{~cm}$ hingga $\pm 50 \mathrm{~cm}$, serta belum adanya lubang pada kerusakan tersebut. Dapat disimpulkan bahwa kerusakan pada tahun 2018 ke 2019 menjadi lebih rusak.

Dari hasil pengamatan dari tahun 2018 sampai tahun 2020, dapat disimpulkan bahwa penanganan kerusakan kurang maksimal sehingga kerusakan menjadi lebih luas dan meningkat keparahanya.

Saran untuk penanganan pada KM +14,600 adalah melakukan Perbaikan Metode P5 (Penambalan Lubang) dengan penggalian dimensi yang lebih meluas dan mendalam ke pondasi/lapisan keras. Hal ini dilakukan untuk mengetahui sumber kerusakan, dan mencegah kerusakan semakin besar. Bila perlu jalan direkonstruksi menjadi perkerasan kaku.

b) Kerusakan $\mathrm{KM}+15,000$

$\mathrm{KM}+15,000$ berada di sebelah sungai yang menghubungkan sungai Ciliwung (Jakarta) dengan sungai Cisadane (Tangerang). Hasil nilai IKP KM ini adalah 46 (Jelek, Poor) untuk Lajur 1. Berikut adalah kondisi kerusakaan pada tahun 2020. Dari hasil penelitian terlihat ada sebuah tambalan dengan panjang \pm 5 meter dan lebar \pm 2 meter. Tambalan tersebut memiliki lubang panjang tingkat Tinggi yang dapat membuat tapak ban kendaraan kecil hingga besar dapat masuk ke lubang tersebut. Kerusakan ini sangat mengganggu kenyamanan berkendara dan menghambat laju kendaraan, karena harus mengurangi kecepatan saat melewati kerusakan tersebut.

Selanjutnya pengecekan di tahun 2019, untuk mengetahui kondisi kerusakan sebelum di tambal sesuai dengan kondisi 2020. Berikut adalah kondisi kerusakan pada tahun 2019. Dari hasil penelitian terlihat bahwa dimensi sama seperti dengan tahun 2020, dengan kerusakan yang lebih ringan. Dapat disimpulkan bahwa kerusakan pada tahun 2019 belum diperbaiki, dan pada tahun 2020 kerusakannya semakin parah karena tidak diperbaiki.

Selanjutnya pengecekan di tahun 2018, untuk mengetahui kondisi kerusakan sebelum di tambal sesuai dengan kondisi 2019. Berikut adalah kondisi kerusakan pada tahun 2018. Dari hasil penelitian terlihat bahwa ada tambalan yang ditambal lagi di atas tambalan tersebut, serta belum adanya lubang besar pada kerusakan tersebut. Dapat disimpulkan bahwa kerusakan sebelum tahun 2018 tidak dibongkar dan langsung ditambal ulang, sehingga pada tahun 2019 tambalan menjadi lebih rusak.

Dari hasil pengamatan dari tahun 2018 sampai tahun 2020, dapat disimpulkan bahwa penanganan kerusakan kurang maksimal sehingga kerusakan menjadi lebih luas dan meningkat keparahanya.

Saran untuk penanganan pada KM +15,000 adalah melakukan Perbaikan Metode P5 (Penambalan Lubang) dengan penggalian dimensi yang lebih meluas dan mendalam ke pondasi/lapisan keras. Hal ini dilakukan untuk mengetahui sumber kerusakan, dan mencegah kerusakan semakin besar.

c) Kerusakan $\mathrm{KM}+15,800$

$\mathrm{KM}+15,800$ berada di sebelah kawasan Daan Mogot City yang dipisahkan oleh sungai yang menghubungkan sungai Ciliwung (Jakarta) dengan sungai Cisadane (Tangerang). Pada tahun 2017 dibangun sebuah jembatan dari kawasan Daan Mogot City dan nyambung ke Jalan Daan Mogot, dikarenakan ada jembatan baru maka perkerasan Jalan Daan 
Mogot mengalami kenaikan elevasi untuk menyeimbangkan dengan jembatan penghubung tersebut. Hasil nilai IKP KM ini adalah 55 (Sedang, Fair) untuk Lajur 2. Berikut adalah kondisi kerusakaan pada tahun 2020. Dari hasil penelitian terlihat banyak retakan memanjang dan melintang. Retakan tersebut membentuk pola persegi panjang yang disebut Retak Blok. Kerusakan ini mengganggu kenyamanan berkendara dan menghambat laju kendaraan, karena harus mengurangi kecepatan saat melewati kerusakan tersebut.

Selanjutnya pengecekan di tahun 2019, untuk mengetahui kondisi kerusakan sebelum di tambal sesuai dengan kondisi 2020. Berikut adalah kondisi kerusakan pada tahun 2019. Dari hasil penelitian terlihat bahwa tidak ada kerusakan pada jalan tersebut. Retakan banyak yang ada pada tahun 2020 belum ada pada tahun 2019 .

Selanjutnya pengecekan di tahun 2017, untuk mengetahui kondisi awal perkerasan saat jembatan baru dibangun. Berikut adalah kondisi perkerasan pada tahun 2017. Dari hasil penelitian terlihat bahwa perkerasan Jalan Daan Mogot telah direkonstruksi menjadi perkerasan kaku yang menggunakan pelat beton. Setelah itu dilapisi aspal untuk menunjang kenyaman berkendara. Dapat disimpulkan bahwa kerusakan Retak Blok pada tahun 2020 diakibatkan adanya pergerakan pada pelat beton dan kerusakan ini disebut Retak Refleksi Sambungan.

Dari hasil pengamatan dari tahun 2017 sampai tahun 2020, dapat disimpulkan bahwa terjadi kerusakan pada pelat beton di bawah perkerasan aspal. Kerusakan pada pelat beton disebabkan oleh beban kendaraan berat yang melaju perlahan di unit sampel tersebut, faktor lainnya adalah adanya akses putar balik sebelum jemabatan tersebut. Kendaraan besar seperti Truk dan Bus dari Kalideres akan berputar balik di putaran tersebut untuk mengarah ke Tangerang, kecepatan kendaraan berat itu akan lambat karena kendaraan baru saja putar balik dan langsung menghadapi kenaikan elevasi jalan, sehingga beban jalan tersebut meningkat.

Saran untuk penanganan pada KM +15,800 adalah melakukan Perbaikan Metode P4 (Pengisian Retak) dengan membongkar lapisan aspal hingga pelat beton terlihat. Selanjutnya mengecek keadaan pelat beton dan melakukan perbaikan sesuai kondisi di lapangan.

\section{KESIMPULAN DAN SARAN}

\section{Kesimpulan}

Berdasarkan penelitian dengan metode Indeks Kondisi Perkerasan pada Jalan Daan Mogot KM +14,000 hingga KM $+16,500$, serta hasil investigasi di beberapa titik kerusakan dengan kasus yang berbeda-beda didapatkan beberapa kesimpulan yaitu:

1. Berdasarkan hasil perhitungan Indeks Kondisi Perkerasan didapatkan nilai IKP terendah adalah 23 (Sangat Parah), dan yang tertinggi adalah 100 (Sangat Baik).

2. Berdasarkan hasil perhitungan didapatkan kerusakan terbanyak pada Tambalan dan Lubang sebanyak masingmasing 38 buah.

3. Berdasarkan hasil perhitungan Indeks Kondisi Perkerasan didapatkan nilai IKP rata-rata Jalan Daan Mogot KM $+14,000 \mathrm{~s} / \mathrm{d}+16,500$ adalah 87,09 (Sangat Baik).

4. Dari hasil investigasi dapat disimpulkan bahwa penyebab kerusakan Tambalan adalah kurang maksimalnya penanganan kerusakan.

5. Dari hasil investigasi dapat disimpulkan bahwa penyebab kerusakan Retakan pada Jalan Daan Mogot depan jembatan penghubung kawasan Daan Mogot City adalah terjadinya kerusakan pelat beton yang berada di bawah aspal. Pelat beton dan aspal tidak kuat menahan beban kendaraan berat yang melaju perlahan saat melewati elevasi kenaikan jalan tersebut, ditambah adanya putaran balik yang membuat kendaraan melaju perlahan di area tersebut.

\section{Saran}

Berdasarkan kesimpulan di atas, maka ada beberapa saran untuk mengatasi persoalan kerusakan pada Jalan Daan Mogot KM +14,000 s/d KM +16,500, yaitu:

1. Lebih sering diadakannya pemeliharaan rutin dan berkala di Jalan Daan Mogot KM +14,000 s/d KM +16,500, untuk meningkatkan kenyamanan serta kemantapan jalan tersebut.

2. Kerusakan-kerusakan yang ada sebaiknya dilakukan pembongkaran meluas dan digali mendalam, untuk mengetahui dan mencegah kerusakan membesar atau meluas. 
3. Perlu adanya perbaikan jalan depan jembatan kawasan Daan Mogot City berupa pembongkaran aspal dan perbaikan pelat beton. Saran lain berupa, pemindahan tempat putar balik menjadi lebih jauh dari jalan depan jembatan tersebut, hal ini dilakukan demi mengurangi beban kendaraan yang lewat.

\section{DAFTAR PUSTAKA}

Neeraj Syal, S. K. (2019). Flexible Pavement. International Research Journal of Engineering and Technology. 3550.

Departemen Pekerjaan Umum Direktorat Jendral Bina Marga. (1997). Tata cara Perencanaan Geometrik Jalan. Jakarta: Departemen Pekerjaan Umum Direktorat Jendral Bina Marga.

Kementrian Pekerjaan Umum dan Perumahan Rakyat. (2016). Penentuan indeks kondisi perkerasan (IKP). Kementrian Pekerjaan Umum dan Perumahan Rakyat.

Kementrian Pekerjaan Umum Direktorat Jenderal Bina Marga. (2011). PERBAIKAN STANDAR untuk PEMELIHARAAN RUTIN JALAN. Jakarta: Kementrian Pekerjaan Umum Direktorat Jenderal Bina Marga.

Permana, R. (2020). Mayor Daan Mogot (1928-1946) Peran dan Perjuangannya. JOURNAL OF SOCIAL SCIENCES \& HUMANITIES “ESTORIA” UNIVERSITAS INDRAPRASTA PGRI. 
